\title{
Neutrophil degranulation and cell lysis is associated with clinical severity in virus-induced asthma
}

\author{
P.A.B. Wark*, S.L. Johnston", I. Moric ${ }^{\natural}$, J.L. Simpson*, M.J. Hensley ${ }^{\S}$, P.G. Gibson ${ }^{\S} *$
}

Neutrophil degranulation and cell lysis is associated with clinical severity in virusinduced asthma. P.A.B. Wark, S.L. Johnston, I. Moric, J.L. Simpson, M.J. Hensley, P.G. Gibson. (C)ERS Journals Ltd 2002.

ABSTRACT: Acute exacerbations of asthma are frequently caused by viral infections, but the inflammatory mechanisms in virus-induced asthma are poorly understood. The aim of the present study was to determine whether viral infection in acute asthma was associated with increased sputum neutrophil degranulation and increased cellular lysis and whether these changes are related to clinical severity.

Adults $(n=49)$ presenting to the emergency department with acute asthma were examined for infection by means of sputum direct-fluorescence antigen detection, sputum culture, and sputum polymerase chain reaction for Mycoplasma, Chlamydia and Legionella pneumophila, and all common respiratory viruses. Subjects infected with one of these agents were classed as having an infective exacerbation. Spirometry and sputum induction were performed on presentation and 4-5 weeks later.

Thirty-seven subjects $(\mathbf{7 6} \%)$ had virus infection and acute asthma. Those with virus infection had increased sputum neutrophils $(\mathbf{p}<0.05)$ and increased neutrophil elastase $(p<0.05)$, this was related to increased elevated sputum lactate dehydrogenase (LDH). Subjects with noninfective asthma had an increase in the proportion of sputum eosinophils. Both groups had elevated sputum eosinophil cationic protein (ECP) concentrations. Higher levels of sputum LDH and ECP were associated with a longer hospital stay.

Virus infection and acute asthma is associated with neutrophilic inflammation, cell lysis and more severe clinical disease.

Eur Respir J 2002; 19: 68-75.
*Airways Research Centre, John Hunter Hospital, Newcastle, Australia. \#Dept of Respiratory Medicine, National Heart and Lung Institute at St Marys, Imperial College School of Medicine, London, UK. Institute for Molecular Genetics and Genetic Engineering, Belgrade, Yugoslavia. ${ }^{\S}$ Faculty of Medicine, University of Newcastle, Newcastle, Australia.

Correspondence: P.G. Gibson, Dept of Respiratory and Sleep Medicine, John Hunter Hospital, Locked Bag 1, Hunter Region Mail Centre, NSW 2310, Australia.

Fax: 61249213469

Keywords: Acute asthma, induced sputum, influenza, respiratory syncytial virus, virus infection

Received: May 72001

Accepted after revision August 22001

This work was funded by Asthma NSW, the National Health and Medical Research Council (Australia) and the John Hunter Hospital Charitable Trust.
While effective treatment of poorly-controlled asthma can be achieved using inhaled corticosteroids, acute exacerbations continue to occur, with community studies showing the majority of these exacerbations to be associated with viral respiratory tract infection $[1,2]$. Respiratory viruses infect bronchial epithelial cells, resulting in epithelial activation and increased neutrophil recruitment and activation [3]. In addition, viruses such as influenza and respiratory syncytial virus (RSV) can cause extensive epithelial necrosis that is enhanced by neutrophils [4]. Necrosis of epithelial cells and granulocytes leads to the release of intracellular contents that may themselves be pro-inflammatory [5]. One of these products is the enzyme lactate dehydrogenase (LDH), which has been used to measure the extent of cell lysis [6]. The mechanisms of acute asthma associated with viral infection, and the influence this has on airway inflammation in acute asthma are not well understood.

The aim of the present study was to determine whether viral infection in acute asthma is associated with increased sputum neutrophil degranulation and increased cellular lysis and whether these changes are related to clinical asthma severity.

\section{Methods}

\section{Subjects}

Adults (n=49) aged 16-74 yrs were recruited within $4 \mathrm{~h}$ of presentation to the emergency room with an acute exacerbation of asthma. Asthma was defined at the initial interview by a respiratory physician based upon a previous physician's diagnosis and American Thoracic Society criteria of a compatible history, together with either bronchial hyperresponsiveness (provocative dose of saline causing a 20\% fall in forced expiratory volume in one second (FEV1) (PD20saline) of $<15 \mathrm{~mL}$ ) or an improvement in FEV1 of $>15 \%$ after $200 \mu \mathrm{g}$ of albuterol. In those subjects with no previous history of asthma, a clinical diagnosis was made initially and confirmed on recovery at Visit 2 by bronchial provocation testing. An acute exacerbation of asthma was based on: 
deterioration in symptoms of wheezing, breathlessness or cough, an increase in the use of short-acting $\beta_{2}$-agonists for relief of symptoms, or a deterioration in self-monitored peak expiratory flow, leading to presentation to the emergency room for treatment of acute asthma. Subjects were excluded if they: were taking regular oral corticosteroids for their asthma, had a coexisting diagnosis by a physician of chronic obstructive pulmonary disease (COPD), had an infiltrate on chest radiography suggesting pneumonia, or had a contraindication to sputum induction.

From February 2-December 1, 1998, 84 individuals agreed to participate. The following subjects were excluded: 10 had been in the emergency room $>4 \mathrm{~h}$ before interview; one had consolidation on chest radiography consistent with pneumonia; nine had diagnosed COPD; one had a pneumothorax complicating their asthma; and three were pregnant. One subject was excluded at follow-up when they were found, upon objective testing, not to have asthma. In addition, 10 subjects were unable to produce an adequate sputum sample for all investigations.

\section{Design}

At Visit 1, a clinical history was taken and spirometry was performed. Next, subjects were pretreated with albuterol and sputum induced, returning 4-5 weeks later when they had symptomatically returned to baseline and were no longer on parenteral corticosteroids (Visit 2). Finally, allergy skin-prick tests, spirometry, bronchial provocation challenges and sputum inductions were performed.

\section{Assessment of asthma}

Asthma severity was determined acutely (Visit 1) on clinical history and severity of airflow limitation as measured by spirometry (Vitalograph Ltd, Buckingham, UK). Previous asthma severity was assessed using the AAs [7] score, which scores severity based on clinical symptoms, exacerbations and medication use. Severity at Visit 2 was assessed by spirometry and degree of airway hyperresponsiveness (PD20saline). Atopy was determined by the presence of at least one immediate reaction to skin-prick testing (weal $\geqslant 3 \mathrm{~mm}$ ), carried out using a 1:10 weight/ volume dilution of 20 common allergens (Bayer Australia Ltd, Pymble, Australia).

\section{Sputum induction}

Sputum induction was carried out only if subjects could perform an adequate FEV1, and if this was $>25 \%$ of the predicted value [8] after pretreatment with $200 \mu \mathrm{g}$ of albuterol delivered via a Volumatic spacer (Allen and Hanbury's, Melbourne, Victoria, Australia). All subjects received supplemental oxygen during sputum induction. Induced sputum was obtained using sterile normal saline $(0.9 \%)$ delivered from a DeVilbiss 2000 ultrasonic nebulizer (DeVilbiss, Oregon, Pike, PA, USA) with 23-cm corrugated tubing, and a Hans Rudolph 2700, two-way nonrebreathing valve box (Hans Rudolph Inc., Kansas City, MO, USA) with a rubber mouthpiece and noseclip. The nebulizer output was $1.8 \mathrm{~mL} \cdot \mathrm{min}^{-1}$ and particle size (mass median aerodynamic diameter) was $<5 \mu \mathrm{m}$. Saline was nebulized for $30 \mathrm{~s}, 1 \mathrm{~min}$ and then for 2-min periods until an adequate sample was obtained. Spirometry was performed $1 \mathrm{~min}$ after each nebulization period, and supplemental albuterol was administered if there was a fall of $\geqslant 20 \%$ in spirometry from baseline. Sputum induction was ceased when the protocol was completed, when an adequate sample was obtained, if spirometry fell below $20 \%$ of baseline and did not recover within $10 \mathrm{~min}$, at the subject's request, or at the investigators' discretion. At Visit 2, sputum was induced using hypertonic saline (4.5\%) as described [9].

\section{Sputum analysis}

Sputum portions were selected from saliva and processed as described [10]. A whole sputum plug was aliquoted and stored at $-70^{\circ} \mathrm{C}$ for virus polymerase chain reaction (PCR). Sputum was dispersed using $0.1 \%$ dithiothreitol (Sputolysin 10\%; Calbiochem Corp., La Jolla, CA, USA), and a total cell count of nonsquamous cells and viability were performed. Supernatant was aspirated and stored at $-70^{\circ} \mathrm{C}$, and cytocentrifuge slides were prepared from the resuspended cell pellet (Shandon Cytospin, Sewickey, PA, USA). A differential count was obtained from 400 cells counted on May-Grünwald-Giemsa stained cytopreps. Eosinophils were enumerated from slides stained with Chromotrope $2 \mathrm{R}$ in the same fashion. Cytokine-positive cells were assessed on periodatelysine-paraformaldehyde fixed slides, incubated with antihuman interleukin (IL)-5 monoclonal antibodies (Pharmingen, San Diego, CA, USA), and detected by the alkaline phosphatase-antialkaline phosphatase technique $[9,10]$. Positive and antibody controls were included in each staining run. The concentration of eosinophil cationic protein (ECP) was determined in thawed sputum supernatant by radioimmunoassay (Kabi Pharmacia Diagnostics AB, Uppsala, Sweden), and IL-8 by enzyme-linked immunosorbent assay (ELISA) (R\&D Systems, Minneapolis, MN, USA). Standard curves were based on dilutions of purified ECP and recombinant IL-8, and the limits of detection of the fluid-phase assays were $2 \mathrm{ng} \cdot \mathrm{mL}^{-1}$ for ECP and $32 \mathrm{pg} \cdot \mathrm{mL}^{-1}$ for IL-8. The activity of free neutrophil elastase was determined with a chromogenic substrate specific for human neutrophil elastase n-methoxysuccinyl-L-alanyl-L-alanyl-L-prolyl-Lvalyl- $p$ niytoanlide (Sigma Chemical Company, St Louis, MO, USA) [11]. Supernatant was sampled neat and reacted with $1 \mathrm{mM}$ substrate. The change in absorbance $\min ^{-1}$ was measured at $405 \mathrm{~nm}$ in a spectrophotometer (Titertek Reg., ICN Biomedicals, Sydney, Australia).

LDH activity was measured in sputum supernatant 
within $2 \mathrm{~h}$ of collection. The LDH activity was measured at $37^{\circ} \mathrm{C}$ by an enzymatic-rate method, using pyruvate as a substrate. The test was performed on a Hitachi 747 analyser (Boehringer-Mannheim, Castle Hill, Sydney, Australia) according to protocol [12]. LDH isoenzymes were measured using electrophoretic separation on agarose gels. After the isoenzymes were separated by electrophoresis, the reaction mixture (D L-lactate $500 \mathrm{mM}$ and oxidized nicotinamide adenine dinucleotide $\left(\mathrm{NAD}^{+}\right) 13 \mathrm{mM}$ ) was layered over the separation medium and incubated at $37^{\circ} \mathrm{C}$. The reduced nicotinamide adenine dinucleotide (NADH) generated over the LDH zones was detected by fluorescence [13].

\section{Microbiological diagnosis}

All subjects with acute asthma had sputum sent for bacterial culture, reverse transcriptase polymerase chain reaction (RT-PCR) and direct fluorescence antigen testing at Visit 1. Sputum was gram stained and then cultured on chocolate blood agar. PCR was performed for the following organisms: rhinoviruses, coronaviruses $229 \mathrm{E}$ and OC43, influenza A and B, parainfluenza 1-3, adenoviruses, RSV, Mycoplasma pneumoniae and Chlamydia pneumoniae. The PCRs were RT-PCRs to detect either genomic or messenger ribonucleic acid (mRNA) specific for the organism. The assays included single-rounded or nested amplification methods and/or internal-probe hybridization as described [14]. Internal controls were used for each PCR run.

For direct fluorescent antigen detection (DFA), the sputum was aliquoted, washed and spotted onto a 10-well slide, and DFA was performed for influenza A and $\mathrm{B}, \mathrm{RSV}$ and parainfluenza $1-3$, according to the manufacturer's instructions (Bartels Viral Diagnostic Panel, Intracel Corp., Issaquah, WA, USA). Acute and convalescent serology was tested for antibodies to $M$. pneumoniae, Legionella pneumophila, $C$. pneumoniae, influenza A and influenza B. The presence of infection was defined by detection of any organism or a four-fold rise in antibody titre.

\section{Statistical methods}

The sputum indices were log transformed to a normal distribution. Comparisons between the groups were carried out using unpaired t-tests. For variables not normally distributed, equivalent nonparametric tests were used. Differences in proportions between groups were analysed by Fisher's exact test or Chisquared. Univariate relationships between continuous variables were analysed by Spearman's rank correlation coefficient (r). Multivariate analysis was carried out on variables after $\log$ transformation. Linear regression was used for continuous variables and logistic regression for dichotomous variables. The results are presented as geometric mean \pm SD. A p $<0.05$ was accepted as statistically significant.

\section{Results}

\section{Viral infection}

An infective cause for acute asthma was identified in 37 subjects $(76 \%): 19(51 \%)$ had RSV, $12(32 \%)$ influenza, four $(11 \%)$ rhinovirus and two $(5 \%)$ coronavirus. In all subjects, bacterial pathogens were not identified on sputum culture; however, oral bacterial commensals were isolated in five subjects. In the subjects with infection and asthma, 35 (95\%) reported that their exacerbation was preceded by a respiratory tract infection within the last 5 days; two were unsure of the precipitant. The 12 subjects who did not have a pathogen identified were defined as having noninfective acute asthma. Of these, five had no acute precipitant and reported deteriorating control for several weeks, five presented on the same night following a spring thunderstorm and two presented after inhaling irritants. None reported symptoms of a respiratory tract infection within the previous month.

\section{Clinical characteristics}

The groups were similar in terms of age, sex, smoking status, atopy, AAS [7] score, dose of inhaled steroids used when stable, and prednisone use for the exacerbation (table 1). Compared to noninfective exacerbations, subjects with infective asthma had a lower FEV1 $(p<0.05)$, were more likely to be admitted to hospital from the emergency room $(\mathrm{p}<0.01)$, and

Table 1.-Clinical characteristics

\begin{tabular}{|c|c|c|c|}
\hline & Noninfective & Infective & Analysis \\
\hline Subjects $n$ & 12 & 37 & NA \\
\hline Male sex & $3(25)$ & $15(41)$ & $\mathrm{p}=0.3$ \\
\hline Age yrs & $37.3 \pm 16.1$ & $40.5 \pm 17.9$ & $\mathrm{p}=0.2$ \\
\hline Smokers & $3(25)$ & $2(17)$ & $\mathrm{p}=0.2$ \\
\hline Atopy & $8(67)$ & $21(57)$ & $\mathrm{p}=0.4$ \\
\hline AAS score [7] & $4.1 \pm 1.0$ & $3.9 \pm 1.4$ & $\mathrm{p}=0.2$ \\
\hline $\begin{array}{c}\text { Maintenance ICS } \\
\mu \mathrm{g} \mathrm{BDP} \cdot \mathrm{day}^{-1}\end{array}$ & $1475 \pm 861$ & $1606 \pm 826$ & $\mathrm{p}=0.8$ \\
\hline Admitted & $4(33)$ & $10(83)^{*}$ & $\mathrm{p}<0.01^{\#}$ \\
\hline $\begin{array}{l}\text { Admitted to } \\
\text { ICU }\end{array}$ & 0 & $2(17)$ & $\mathrm{p}=0.2^{\#}$ \\
\hline $\begin{array}{l}\text { Length of stay } \\
\text { in days }\end{array}$ & $0.7 \pm 1.4$ & $4.7(5.9)^{*}$ & $\mathrm{p}=0.02$ \\
\hline $\begin{array}{l}\text { Acute FEV } 1 \\
\% \text { pred }\end{array}$ & $70.4 \pm 24$ & $45.3 \pm 31.7^{*}$ & $\mathrm{p}=0.04$ \\
\hline $\begin{array}{l}\text { FEV1 \% pred } \\
\text { at follow-up }\end{array}$ & $86.5 \pm 23.1$ & $70.1 \pm 31.2^{*}$ & $\mathrm{p}=0.04$ \\
\hline $\begin{array}{l}\text { Maintenance ICS } \\
\text { at follow-up } \\
\mu \mathrm{g} \text { BDP. day }\end{array}$ & $1523 \pm 806$ & $1865 \pm 886$ & $\mathrm{p}=0.5$ \\
\hline
\end{tabular}

Data are presented as $\mathrm{n}(\%)$ or mean \pm SD unless otherwise stated. ICS: inhaled corticosteroids; BDP: beclomethasone dipropionate; ICU: intensive care unit; FEV1: forced expiratory volume in one second; NA: not applicable. ": ICS dose expressed as total daily dose of BDP in $\mu \mathrm{g} \cdot \mathrm{day}^{-1}$, where $1 \mu \mathrm{g}$ BDP equals $1 \mu \mathrm{g}$ budesonide and $0.5 \mu \mathrm{g}$ fluticasone. $*: \mathrm{p}<0.05$, significantly different from those with noninfective acute asthma; \#: analysis using Chi-squared test. 


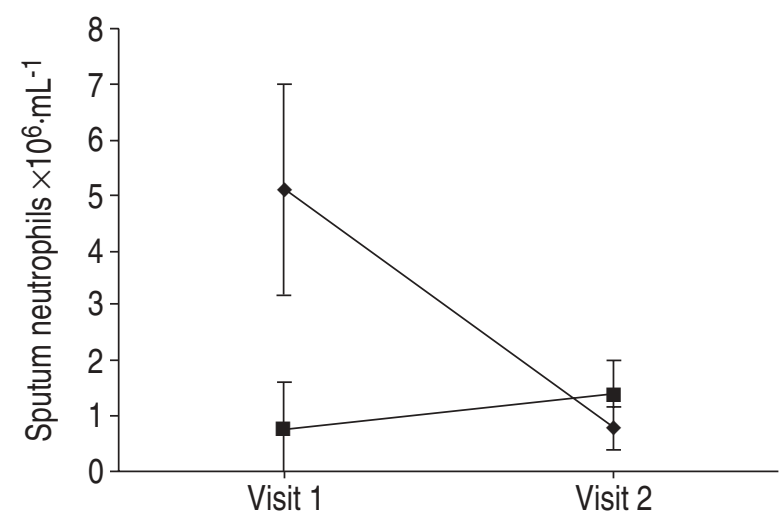

Fig. 1. - Induced sputum neutrophils (measured as number of cells $\times 10^{6} \cdot \mathrm{mL}^{-1}$ ) in subjects with acute asthma (Visit 1) and upon recovery Visit 2). The points represent the geometric mean \pm $1 \mathrm{SEM}$. Subjects with infective asthma $(\diamond)$ had higher sputum neutrophils at Visit 1 compared to noninfective asthma $(\mathrm{p}=0.02)$. By Visit 2, sputum neutrophils had fallen in subjects with infective asthma $(\mathrm{p}=0.04)$, but no significant change was seen in subjects with noninfective asthma.

subsequently had a longer stay in hospital (table 1, $\mathrm{p}=0.02$ ). By Visit 2, subjects with infective asthma still had a lower FEV1 (table 1).

\section{Airway inflammation}

Subjects with infective acute asthma had significantly increased sputum neutrophils compared with noninfective acute asthma at Visit 1 (fig. 1 and table 2, $\mathrm{p}<0.05$ ). By Visit 2, sputum neutrophils had fallen in infective asthma, but were unchanged in noninfective asthma (fig. 1 and table 2, p=0.04). Subjects with noninfective asthma had an elevated sputum eosinophil percentage compared to the other groups with infective asthma at Visit 1 (table 2, $\mathrm{p}<0.05$ ); however,

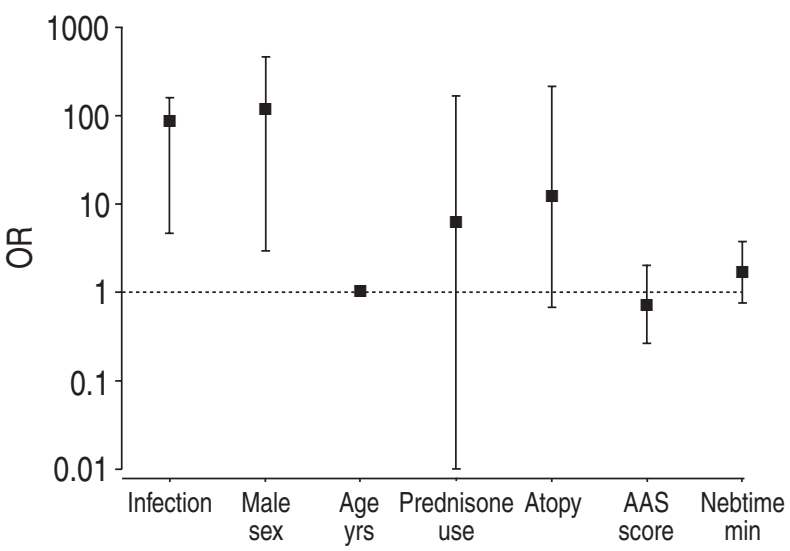

Fig. 2. - Logistic regression model to predict variables associated with increased sputum neutrophils. An increase in sputum neutrophils was defined as $>3.1 \times 10^{6} \cdot \mathrm{mL}^{-1}$. The points represent the odds ratio (OR) and their $95 \%$ confidence intervals. ……... the line of unity. The presence of infection and male sex independently predicted the presence of elevated sputum neutrophils at Visit 1.

absolute eosinophils were elevated in both groups. A logistic regression analysis was performed to determine whether the presence of infection, independently predicted, increased sputum neutrophils. An increase in sputum neutrophils was defined as $>3.1 \times 10^{6} \cdot \mathrm{mL}^{-1}$, which is 2 standard deviations (SD) above the mean for normals [15]. Increased sputum neutrophils were predicted by the presence of infection (odds ratio (OR): 86, 95\% confidence interval (CI): 5-159) and male sex (OR: 118, 95\% CI: 3-468), independent of age, smoking status, prednisone use at presentation, atopy, AAs [7] severity score and the time nebulized saline was given to induce sputum (fig. 2).

Subjects with infective acute asthma had significantly higher sputum neutrophil elastase compared to

Table 2. - Sputum cell counts in acute asthma

\begin{tabular}{|c|c|c|c|c|}
\hline & \multicolumn{2}{|c|}{ Visit 1} & \multicolumn{2}{|c|}{ Visit 2} \\
\hline & Noninfective & Infective & Noninfective & Infective \\
\hline Nebulizer time min & $2.6 \pm 1.7$ & $2.8 \pm 1.9$ & $4.8 \pm 1.6$ & $4.9 \pm 1.6$ \\
\hline $\mathrm{TCC} \times 10^{6} \cdot \mathrm{mL}^{-1}$ & $2.8 \pm 2.9$ & $8.3 \pm 2.5^{*}$ & $3.3 \pm 2.2$ & $2.2 \pm 1.5^{* * *}$ \\
\hline Neutrophils $\times 10^{6} \cdot \mathrm{mL}^{-1}$ & $0.8 \pm 5$ & $5.1 \pm 12.1 *$ & $1.4 \pm 2.2$ & $0.8 \pm 3.4^{* * *}$ \\
\hline Neutrophils $\%$ & $31.6 \pm 2.5$ & $63.1 \pm 3.2$ & $36.6 \pm 2$ & $39.8 \pm 1.6$ \\
\hline Eosinophils $\times 10^{6} \cdot \mathrm{mL}^{-1}$ & $0.2 \pm 4.5$ & $0.2 \pm 2.5$ & $0.01 \pm 4.5$ & $0.03 \pm 2.5$ \\
\hline Eosinophils \% & $7.2 \pm 3.3^{\#}$ & $1.5 \pm 3.4$ & $2.5 \pm 2 * * *$ & $1.2 \pm 6.7$ \\
\hline Macrophages \% & $40.5 \pm 1.8$ & $18.2 \pm 3.7$ & $44.7 \pm 1.5$ & $45.7 \pm 2$ \\
\hline Lymphocytes \% & $1.1 \pm 2.2$ & $1.1 \pm 2.5$ & $1.7 \pm 2$ & $1 \pm 3$ \\
\hline Epithelial cells \% & $2.7 \pm 2.7$ & $3.3 \pm 5.5$ & $1.4 \pm 1.3$ & $2.2 \pm 6.1$ \\
\hline Squamous cells $\%$ & $4.9 \pm 2.7$ & $4.6 \pm 3.1$ & $5 \pm 3.3$ & $4.4 \pm 1.2$ \\
\hline IL-8 ng. $\mathrm{mL}^{-1}$ & $20.9 \pm 5.5$ & $35 \pm 3.7$ & $11.8 \pm 6.1$ & $17.8 \pm 6.1$ \\
\hline IL-5 positive cells $\%$ & $15.6 \pm 1.8^{\#}$ & $8.4 \pm 1.6$ & $2 \pm 0.4$ & $1.4 \pm 1.8$ \\
\hline $\mathrm{ECP} \mathrm{ng} \cdot \mathrm{mL}^{-1}$ & $3072 \pm 55$ & $3090 \pm 49$ & $460 \pm 5 * * *$ & $398 \pm 18$ \\
\hline Neutrophil elastase $\mu \mathrm{g} \cdot \mathrm{mL}^{-1}$ & $169 \pm 3.3$ & $3129 \pm 7.4 *$ & $100 \pm 2.5$ & $120 \pm 9.6^{* * *}$ \\
\hline $\mathrm{LDH} \mathrm{IU} \cdot \mathrm{mL}^{-1}$ & $182 \pm 2.2$ & $550 \pm 16^{*}$ & $54 \pm 12.7 * * *$ & $64 \pm 1.9 * * *$ \\
\hline
\end{tabular}

Data are presented as mean \pm SD. TCC: total cell count; IL: interleukin; ECP: eosinophil cationic protein; LDH: lactate dehydrogenase; IU: international units. The analysis was carried out using unpaired t-tests on log-transformed data. *: $\mathrm{p}<0.05$, significantly higher than subjects with noninfective acute asthma at Visit $1 ;{ }^{*}: \mathrm{p}<0.05$, significantly higher than subjects with infection and acute asthma at Visit $1 ; * * *: \mathrm{p}<0.001$, significantly lower than Visit 1. 


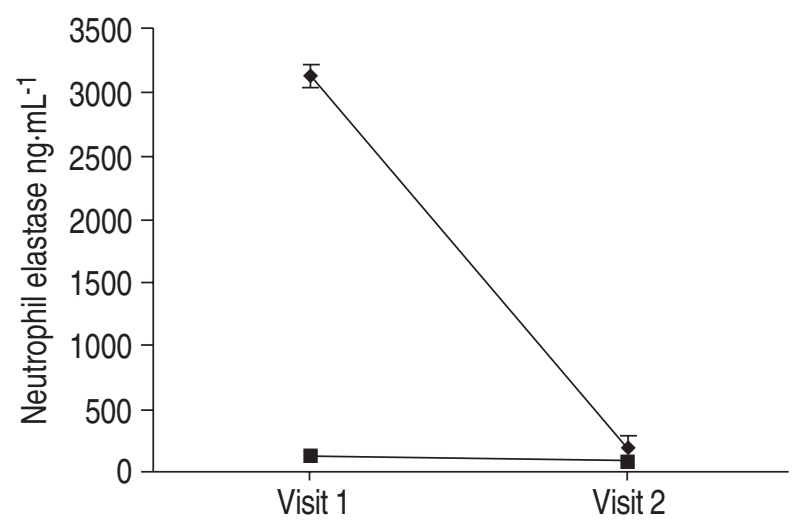

Fig. 3.-Sputum neutrophil elastase $\left(\mathrm{ng} \cdot \mathrm{mL}^{-1}\right)$ in subjects with acute asthma (Visit 1) and upon recovery (Visit 2). The points represent the geometric mean \pm 1 SEM. Subjects with infective asthma $(\diamond)$ had higher sputum neutrophil elastase at Visit 1 compared to noninfective asthma $(\square)(\mathrm{p}<0.05)$. By Visit 2, this had fallen in subjects with infective asthma $(\mathrm{p}<0.05)$, but no significant change was seen in subjects with noninfective asthma.

subjects with noninfective acute asthma at Visit 1 (table 2 and fig. 3), and this had fallen significantly by Visit 2 (table 2).

Subjects with noninfective acute asthma had a greater proportion of cells staining positive for IL-5 than the groups with infection and acute asthma. Sputum ECP was elevated in both groups at Visit 1 (table 2), and this had fallen significantly by Visit 2 (table 2, p<0.05). IL-8 was elevated at Visit 1 in both groups, and it was closely correlated to increased neutrophils $(\mathrm{r}=0.68, \mathrm{p}<0.01)$.

\section{Sputum lactate dehydrogenase}

Sputum LDH activity was significantly higher in the groups with infection and acute asthma compared to those with noninfective acute asthma (table 2 and fig. $4, \mathrm{p}<0.05)$, but it had fallen significantly in all

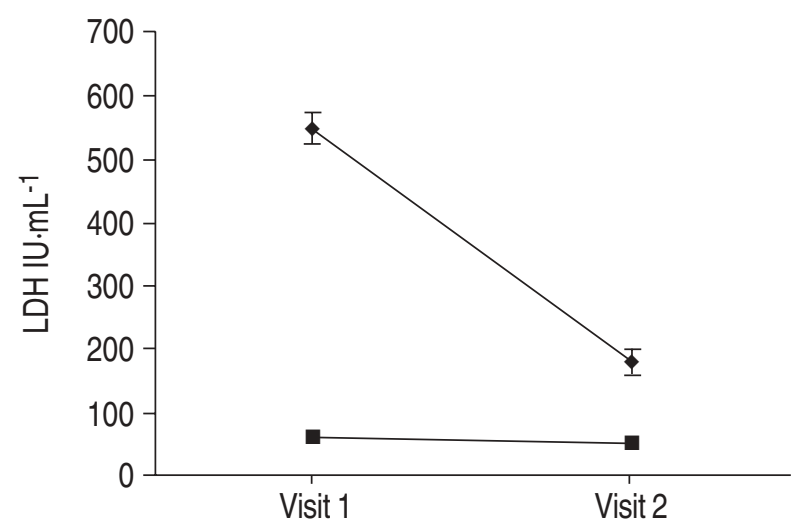

Fig. 4.-Mean sputum lactate dehydrogenase (LDH) in subjects at Visit 1 and Visit 2. The points represent the geometric meant 1 SEM. Subjects with infective asthma $(\bullet)$ had higher sputum $\mathrm{LDH}$ at Visit 1 compared to noninfective asthma $(\mathbf{\square})(\mathrm{p}<0.05)$. By Visit 2, sputum LDH had fallen significantly in all subjects $(\mathrm{p}<0.05)$. IU: international units.

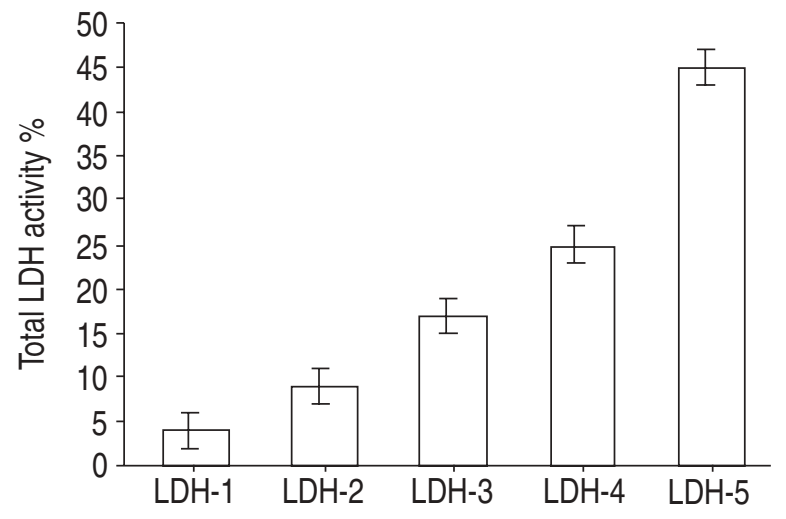

Fig. 5.-Sputum lactate dehydrogenase (LDH) isoenzymes expressed as a per cent of the total LDH activity at the initial visit. Data are presented as medians and interquartile ranges.

groups by Visit 2 (fig. 5 and table 2). The predominant isoenzyme present was LDH-5, which comprised a median $45 \%$ (interquartile range (IQR) 39-48) of the total LDH (fig. 5). The median ratio of $\mathrm{LDH}-4$ to LDH-5 was 0.57 (IQR $0.48-0.59$ ) and the ratio of LDH-3 to LDH-5 was 0.42 (IQR $0.35-0.44$ ).

Elevated sputum LDH activity was closely correlated with increased sputum neutrophils ( $\mathrm{r}=0.81$, $\mathrm{p}<0.001)$, neutrophil elastase $(\mathrm{r}=0.75, \mathrm{p}<0.001)$ and, to a lesser extent, sputum ECP ( $\mathrm{r}=0.43, \mathrm{p}=0.02)$, but not sputum eosinophils ( $\mathrm{r}=-0.06, \mathrm{p}=0.8)$. In a multivariate linear regression model (table 3 ), increased sputum neutrophils were independently associated with higher levels of sputum LDH activity, with the model predicting $79 \%$ of the variation in sputum LDH.

\section{Relationships between airway inflammation and severity of acute asthma}

A linear regression model showed that a longer hospital stay was predicted by elevated sputum LDH, ECP and more severe pre-existing asthma, as measured by the AAs [7] score, independent of age, sex, smoking status and prednisone use at presentation (table 4). This model accounted for $80 \%$ of the variability in length of stay.

Table 3.-Linear regression analysis to predict sputum lactate dehydrogenase (LDH)

\begin{tabular}{lrcc}
\hline Log LDH IU $\cdot \mathrm{mL}^{-1}$ & Coefficient & $\begin{array}{c}\text { Standard } \\
\text { error }\end{array}$ & $\mathrm{P}>\mathrm{t}$ \\
& & 0.1 & $\mathrm{p}=0.001$ \\
Log neutrophils $\times 10^{6} \cdot \mathrm{mL}^{-1}$ & 0.42 & 0.18 & $\mathrm{p}=0.06$ \\
Log eosinophils $\times 10^{6} \cdot \mathrm{mL}^{-1}$ & -0.18 & 0.09 & $\mathrm{p}=0.2$ \\
Log ECP ng $\cdot \mathrm{mL}^{-1}$ & 0.21 & 0.15 & $\mathrm{p}=0.5$ \\
Log neutrophil elastase & 0.02 & 0.08 & $\mathrm{p}=0.09$ \\
Log IL-8 ng $\cdot \mathrm{mL}^{-1}$ & 0.33 & 0.18 & $\mathrm{p}=0.059$ \\
Constant & 2.2 & 1.1 & $\mathrm{p}=0.059$ \\
\hline
\end{tabular}

IU: international units; ECP: eosinophil cationic protein; IL: interleukin. Probability $F>0.0001$, adjusted $\mathrm{R}^{2}=0.787$. 
Table 4. - Linear regression analysis to predict length of hospital stay in acute asthma

\begin{tabular}{lccc}
\hline Length of stay days & Coefficient & $\begin{array}{c}\text { Standard } \\
\text { error }\end{array}$ & $\mathrm{P}>\mathrm{t}$ \\
& & & \\
\hline Log neutrophils $\times 10^{6} \cdot \mathrm{mL}^{-1}$ & 0.44 & 0.37 & $\mathrm{p}=0.3$ \\
Log eosinophils $\times 10^{6} \cdot \mathrm{mL}^{-1}$ & -0.31 & 0.25 & $\mathrm{p}=0.3$ \\
Log LDH IU $\cdot \mathrm{mL}^{-1}$ & 2.56 & 0.6 & $\mathrm{p}=0.002$ \\
Log ECP ng $\cdot \mathrm{mL}^{-1}$ & 1.19 & 0.4 & $\mathrm{p}=0.02$ \\
Log neutrophil elastase & 0.10 & 0.21 & $\mathrm{p}=0.6$ \\
Age yrs & 0.03 & 0.02 & $\mathrm{p}=0.3$ \\
Sex & -1.3 & 0.62 & $\mathrm{p}=0.06$ \\
Smoking status & 1.7 & 0.86 & $\mathrm{p}=0.08$ \\
Prednisone use & 0.85 & 0.73 & $\mathrm{p}=0.3$ \\
AAS severity score [7] & -0.82 & 0.34 & $\mathrm{p}=0.04$ \\
Constant & -1.97 & 3.15 & $\mathrm{p}=0.549$ \\
\hline
\end{tabular}

LDH: lactate dehydrogenase; IU: international units; ECP: eosinophil cationic protein. Probability $\mathrm{F}=0.004$, adjusted $\mathrm{R}^{2}=0.797$.

\section{Discussion}

In acute asthma with viral infection, there was intense sputum neutrophil influx and degranulation, along with elevated ECP. In contrast, acute asthma due to noninfective causes was characterized by increased IL-5 and eosinophil activation, but not the same intense neutrophil response. Sputum neutrophils were associated with increased cell lysis, measured by sputum LDH. Increased sputum LDH and ECP were associated with a longer hospital stay, implying more severe and protracted acute asthma.

The authors recruited consecutive adults, who presented to the emergency room for treatment of an exacerbation of asthma. The diagnoses of asthma and an acute exacerbation of asthma were initially made independently by the emergency room staff and confirmed by a respiratory physician. All of the subjects had significant airway obstruction and deterioration in clinical symptoms, and required treatment with parenteral corticosteroids.

The high prevalence of viral infection in acute asthma is consistent with the work of others [1,2]. However, these studies included mild exacerbations and found rhinovirus to be present most commonly. In contrast, the present study was performed in a hospital-based cohort with severe exacerbations of asthma and found that the most prevalent pathogens were RSV and influenza. The reason for this difference is unclear. The 11-month recruitment period should have been sufficient to encompass the seasonal variation in viral infections. One explanation that can be proposed is that infection with RSV and influenza may cause more severe clinical exacerbations of asthma. Influenza is well known as an important pathogen in adults, responsible for significant morbidity and mortality in patients with chronic respiratory disease [16]. While RSV has mostly been thought of as an infection in infants, it has become increasingly recognized as a pathogen in adults, responsible for prolonged symptoms of cough and wheezing along with excess mortality and morbidity in those with chronic respiratory disease similar to influenza [17].
Alternatively, the study may have been done during a year of particularly prevalent RSV infection, leading to the higher rate of detection. This important issue will need to be defined further in larger populationbased studies in order to determine whether the type of viral pathogen contributes to clinical severity.

Sputum induction was used to assess airway inflammation, as it is safe and gives acceptable results in acute exacerbations of asthma $[10,18]$. In the present study, the methods used to induce sputum differed between visits, as $0.9 \%$ saline was used at Visit 1 , while at Visit 2, induction was done during bronchial provocation challenge with $4.5 \%$ saline. Prior work has established that the tonicity of saline has no effect on cellular differentials [19]. However, the time taken to induce sputum can influence the cell count [20]. To ensure comparability between samples, there were no differences in nebulization time between the groups at either visit, and nebulization time at Visit 2 did not exceed $4 \mathrm{~min}$ from Visit 1 . This potentially could still influence the proportion of sputum neutrophils, but not the absolute cell counts or proportions of eosinophils when comparing Visit 1 with Visit 2 [20]. The validity of this assertion was confirmed by regression analysis (fig. 2). Sputum quality, cell viability and squamous contamination did not differ between visits.

The diagnosis of infection was based on the ability to detect the organism by PCR on induced sputum. In this context, viral culture may not be sensitive enough to detect viruses, particularly picornaviruses, while PCR is both sensitive and specific [21] and is validated in asthma exacerbations [1, 2]. Internal controls for the PCR were used at the time of testing samples from Visit 1 . The validity of these virus detection methods is also consistent with the literature, which reports that rhinoviruses can be detected as frequently in the lower respiratory tract as in the upper when the same sampling and detection methods are used in the same subjects [22]. Subjects also had DFA testing for influenza, RSV and parainfluenza, along with acute and convalescent serology for influenza. All subjects who were positive on DFA or who seroconverted, were positive on PCR. In addition, $95 \%$ of the subjects with organisms detected, reported symptoms consistent with a recent infection, compared to none in the group in whom an organism could not be detected.

This study demonstrates that the mechanisms of virus-induced exacerbation differ from those of noninfective acute asthma with increased neutrophilic inflammation. Those with infection had an intense neutrophil infiltrate and degranulation that was not seen in those with noninfective asthma. However, sputum ECP was elevated to a similar degree in both groups. A prominent neutrophil influx in acute asthma has been reported previously [3, 10, 23], although only one previous study has directly linked neutrophil influx to viral infection [24]. This is consistent with experimental viral infections of bronchial epithelial cells, where viral infection induces production of IL-8 [25] as well as an influx of neutrophils [26].

In subjects with acute asthma, the neutrophilic inflammation correlated with elevated sputum LDH. 
LDH is a cytoplasmic enzyme present in all major cell types and is released upon cell lysis [27]. Potential sources are influx from serum due to increased vascular permeability or the necrosis of epithelial and inflammatory cells. Isoenzyme analysis was done to further elucidate the likely LDH source. Serum predominantly contains LDH-1 and LDH-2 [6]. These isoenzymes were comparatively low in sputum supernatant, and the total level of LDH activity present in sputum of the subjects with infection and acute asthma was much higher than would be expected in serum, making transudation an unlikely mechanism. The isoenzymes of LDH present in the normal lung are LDH-1 (10\%), LDH-2 (20\%), LDH-3 (30\%), LDH-4 (25\%), and LDH-5 (15\%) [6], while blood eosinophils have low levels of LDH-5 [28]. In contrast, LDH-5 is the main isoenzyme seen in neutrophilic lung inflammation, such as bacterial pneumonia [29]. The present authors have shown that acute asthma, due to virus infection, was associated with an increase in LDH-5, thus suggesting that neutrophils are a major source of LDH activity. Activated neutrophils have the potential to cause cell lysis in experimental models [30]. In addition, both RSV [4] and influenza [16] lead to airway inflammation and epithelial cell lysis. Infection has also been shown to promote neutrophil adhesion to infected epithelial cells, thus augmenting the damage [4]. This is in keeping with the present results where there was intense LDH activity at Visit 1, suggesting cell lysis, which was highest in those with infection and correlated closely with neutrophilic inflammation.

Increased LDH activity at presentation with acute asthma was associated with more severe clinical disease. In fact, increased LDH activity, along with elevated sputum ECP, and the severity of pre-existing asthma were independent predictors of length of hospital stay, taking into account other inflammatory markers, age, sex, smoking status and prednisone use. This implies that the degree of cell lysis as a consequence of airway inflammation and virus infection is an important early predictor of more severe and protracted acute asthma. It may also reflect a type of airway inflammation less responsive to corticosteroids. This indicates a potential role for sputum LDH measurement to predict clinical course in acute asthma.

In conclusion, acute asthma with virus infection is characterized by an intense neutrophil influx, with neutrophil degranulation and cell lysis. Both infective and noninfective asthma had elevated sputum eosinophil cationic protein, suggesting eosinophil degranulation. Virus infection and the subsequent mixed inflammatory infiltrate with elevated sputum lactate dehydrogenase are acutely associated with more severe airway obstruction and prolonged hospitalization.

\section{References}

1. Johnston SL, Pattemore PK, Sanderson G, et al. Community study of the role of viral infections in exacerbations of asthma in 9-11 year old children. BMJ 1995; 310: 1225-1228.

2. Nicholson KG, Kent J, Ireland DC. Respiratory viruses and exacerbations of asthma in adults. $B M J$ 1993; 307: 982-986.

3. Teran LM, Johnston SL, Schroder J-M, Church MK, Holgate ST. Role of nasal interleukin-8 in neutrophil recruitment and activation in children with virusinduced asthma. Am J Respir Crit Care Med 1997; 155: 1362-1366.

4. Wang SZ, Xu H, Wraith A, Bowden JJ, Alpers JH, Forsyth KD. Neutrophils induce damage to respiratory epithelial cells infected with respiratory syncytial virus. Eur Respir J 1998; 12: 612-618.

5. Chilvers ER, Rossi AG, Murray J, Haslett C. Regulation of granulocyte apoptosis and implications for antiinflammatory therapy. Thorax 1998; 53: 533-534.

6. Drent M, Cobben NAM, Henderson RF, Wouters EFM, van Dieijen-Visser M. Usefulness of lactate dehydrogenase and its isoenzymes as indicators of lung damage or inflammation. Eur Respir J 1996; 9: $1736-1742$.

7. Aas K. Heterogeneity of bronchial asthma. Allergy 1981; 36: 3-14.

8. Knudson RJ, Slavin RC, Lewowitz MD, Burrows B. The expiratory flow-volume curve. Normal standards, variability and effect of age. Am Rev Respir Dis 1976; 113: 587-600.

9. Gibson PG, Wlodarczyk J, Hensley MJ, et al. Epidemiological association of airway inflammation with asthma symptoms and airway hyperresponsiveness in childhood. Am J Respir Crit Care Med 1998; 158: $36-41$.

10. Twaddell SH, Gibson PG, Carty K, Wolley KL, Henry RL. Assessment of airway inflammation in children with acute asthma using induced sputum. Eur Respir J 1996; 9: 2104-2108.

11. Fahy JV, Schuster A, Uki I, Boushey HA, Nadel JA. Mucus hypersecretion in bronchiectasis the role of neutrophil protease. Am Rev Respir Dis 1992; 146: $1430-1433$.

12. van der Heiden C, Bais R, Gerhardt W, Lorentz K, Rosalki S. Approved recommendation on IFCC methods for the measurement of catalytic concentration of enzymes. Part 8. IFCC method for lactate dehydrogenase. Euro J Clin Chem Clin Biochem 1994; 32: 639-655.

13. McKenzie D, Henderson AR. Electrophoresis of lactate dehydrogenase isoenzymes. In: American Association of Clinical Chemistry. Washington, D.C., GR Cooper, 1983.

14. Chauhan AJ, Johnston SL. Advances in the diagnosis of respiratory viral infections. In: Skoner $\mathrm{D}$, ed. Asthma And Respiratory Infections. New York, Marcell Dekker, 2000; pp. 221-244.

15. Spanevello A, Confalonieri M, Sulotto F, et al. Induced sputum cellularity. Reference values and distribution in normal volunteers. Am J Respir Crit Care Med 2000; 162: 1172-1174.

16. Treanor JJ, Influenza A, B viruses. In: Lenfant C, ed. Viral Infections of the Respiratory Tract. New York, Marcell Dekker, 1999; pp. 105-160.

17. Hall C. Respiratory syncytial virus and parainfluenza virus. $N$ Engl J Med 2001; 344: 1917-1928.

18. Fahy JV, Kim KW, Liu J, Boushey HA. Prominent neutrophilic inflammation in sputum from subjects 
with asthma exacerbation. $J$ Allergy Clin Immunol 1995; 95: 843-852.

19. Bacci E, Cianchetti PL, Paggaro S, et al. Comparison between hypertonic and isotonic saline-induced sputum in the elevation of airway inflammation in subjects with moderate asthma. Clin Exp Allergy 1996; 26: $1395-1400$.

20. Gerschman NH, Liu H, Wong HH, Liu JT, Fahy JV. Fractional analysis of sequential induced sputum samples during sputum induction: evidence that different lung compartments are sampled at different time points. J Allergy Clin Immunol 1999; 104: 322-328.

21. Johnston SL, Sanderson G, Pattemore PK, et al. Use of polymerase chain reaction for the diagnosis of picornavirus infection in subjects with and without respiratory symptoms. J Clin Microbiol 1993; 31: 111-117.

22. Papadopoulos NG, Bates PJ, Bardin PG, et al. Rhinoviruses infect the lower airways. J Infect Dis 2000; 181: 1875-1884.

23. Ordonez CL, Shaughnessy TE, Matthay MA, Fahy JV. Increased neutrophil numbers and IL-8 levels in airway secretions in acute asthma. Am J Respir Crit Care Med 2000; 161: 1185-1190.

24. Pizzichini MMM, Pizzichini E, Efthiamiadis A, et al. Asthma and natural colds inflammatory indices in induced sputum: a feasibility study. Am J Respir Crit Care Med 1998; 158: 1178-1184.
25. Mastronarde JG, Monick MM, Hunninghake GW. Oxidant tone regulates IL-8 production in epithelium infected with respiratory syncytial virus. Am J Respir Cell Mol Biol 1995; 13: 237-244.

26. Trigg CJ, Nicholson KG, Wang JH, Ireland DC, Jordan S, Duddle JM. Bronchial inflammation and the common cold: a comparison of atopic and non-atopic subjects. Clin Exp Allergy 1996; 26: 665676.

27. Glick JH. Serum lactate dehydrogenase isoenzyme and total lactate dehydrogenase values in health and disease, and clinical evaluation of these tests by means of discriminant analysis. Am J Clin Pathol 1969; 52: 320-328.

28. De Simone C, Ferrari M, Sorice F. LDH isoenzyme distribution in human eosinophils. Int Arch Allergy Appl Immunol 1983; 71: 193-199.

29. Cobben NAM, Jacobs JA, van Dieijen-Visser MP, Mulder PGH, Wouters EFM, Drent M. Diagnostic value of BAL fluid cellular profile and enzymes in infectious pulmonary disorders. Eur Respir J 1999; 14: 496-502.

30. Tung DKL, Bjursten LM, Zweifach BW, SchmidSchonbein GW. Leukocyte contribution to parenchymal cell death in an experimental model of inflammation. J Leuk Biol 1997; 62: 163-175. 